\title{
Is the Community a Medium? Is "That's Me!" the Message? The Story Of \#Placevent: We Are Using Social Media to Hack the Academy
}

\section{Valentina Bazzarin}

University of Bologna, Italy

doi: 10.7358/ijtl-2015-001-bazz

valentina.bazzarin@unibo.it

\begin{abstract}
University students attending socio-humanistic classes are frequently demanding an actual opportunity to apply their digital skills, their informal education and their innovative ideas about communications to local companies and public bodies. Their expectation is to find or to create job opportunities in a depressing national framework. In January 2013 we started a "Workshop for events planning and students' placement", quickly replaced with the hashtag \#placevent. We run a research/action plan observing and collecting students' self and community representation, using both digitalethnographic methods and assigning them problem-solving tasks. We suppose that ritual practices of the Internet interaction are developing, although these have not been codified, because in any community we can observe a process supporting and enhancing shared social meanings and identities. Additionally, we found that individuals may belong to and identify with more than one community contemporaneously and serially, changing affiliations with great fluidity. The main result of this activity is that students feel empowered by witnessing their belonging to a group promoting innovation through practices of communication, as well as by overlapping and matching networks of relationship and widening the community or engaging new shareholders.
\end{abstract}

Keywords: community; social media; social networks; digital humanities; job market; hacking.

\section{INTRODUCTION}

According to Florida "universities are amazingly effective talent magnets. By attracting eminent researchers and scientists, universities in turn attract graduate students, generate spin-off companies, and encourage other companies to 
locate nearby in a cycle of self-reinforcing growth". (Florida 2011,310) University of Bologna is attracting talents since 1088 A.D., but the link between Alma Mater's brand in terms of power of attraction and the real opportunity to exploit fellows' potential in the job market weakend in the last years, especially for the humanities' class. Students attending the Master degree in Social and Public Communication Studies at the University of Bologna, ask for a specific opportunity to show their skills and their innovative ideas about communications to local companies and public bodies. Their hope is to find a link with the job market before they complete their final dissertation. A general lack of professional experience is common in fellows' resumes and they all need professional advices as well as an open access to a network of relationships before the end of the "education chapter" of their curricula. However, both the Italian academic system and the traditional role of "professors" (we are not advisors or a mentors) let graduate students face the job-market almost alone. On the other side small as well as big companies use to close doors in front of students' enthusiastic request for training, denying any opportunity of reciprocal growth, explaining that there are not positions for people with a humanistic background and without any prove work experience.

Master degree in Social and Public Communication Studies has a strong record of innovative workshops aimed to complete students' route exploring theories with practical experiences. Placevent is a pilot answer to students' request to break the rules. A weekly two-hours-workshop started at the end of January 2013 and the original name of the activity was "Workshop for events' planning and students' placement", quickly replaced with the hashtag: \#placevent. The virtual places in which students completed their homework and the group used to segment the job-market and to define their position were a blog (placevent.wordpress.com), a YouTube channel where they still upload the videos they produce, and a @placevent account in the main social media: Twitter, Flickr, Instagram, Facebook (both with a closed community and an open page to share the event they were required to organize to obtain the credits) and also LinkedIn, where every student is publishing individually, improving their personal resumes and scouting open positions, information and best practices.

The workshop vision is similar to the one Gideon Burton has put pen (i.e. keyboard) to paper (i.e. doc) in 'Hacking the Academy - A Book Crowd-sourced in One Week': "Dear students: I'm about to say something a college professor shouldn't say to his students, but I care about you a lot so I'm prepared to break the code and say what needs to be said: Your college experience is likely to set back your education, your career, and your creative potential. Ironically, this will be done in the name of education. You deserve to know about this! You have what it takes to reclaim, reform, and remix your education. Don't let college unplug your future! [...] It will be a long time 
before a college diploma is as quaint as, say, getting a public notary's stamp. But there is another system already competing with college, and it will start those bean counters in the tuition office sweating soon enough. This alternative to college credentials is as huge as the Stay Puft marshmallow man from Ghostbusters and he's towering over the skyline right where town meets gown: online identity. That's right. Who you are and what you've done will in the very near future be so well documented by your online activities that a resume will be redundant. The time will come when a college degree will be suspect if not complemented by an admirable online record-and I'm not talking about transcripts. Your "transcripts" will consist of your life stream: your blog, your social networks, your creative work published or otherwise represented online. Cyberspace is already more real to you than the physical space of your college campus-it is becoming so for your future employers ${ }^{1}$."

Indeed in 2013 Neelie Kroes, Vice-President of the European Commission responsible for the Digital Agenda, in Warsaw, Poland, declared too: "the main priority has to be dealing with high unemployment. Far too many people are out of work; including 5 million young people. And those aren't just people missing out on jobs. They are missing new opportunities, on getting their own place, on starting their own family. In short, they are missing out on life chances. In that context, boosting digital skills is essential. It helps people find the jobs available: and remember that, in our digital age, almost one million ICT jobs risk going unfilled. It helps our economic competitiveness, ensuring our economy continues to create jobs into the future. And it is well suited to the young generation, of digital natives ${ }^{2} . "[\ldots]$ "First, we can ensure people know that ICT careers are an attractive career option. Today, many don't even realise that. Especially, I'm sorry to say, women. Second, they need basic ICT training embedded in their education. Because those fundamental digital skills are like reading and writing - essential for almost any job today, and certainly for ICT jobs. Third, they need somewhere to train. Not just in some faraway university, but close to home. Fourth, once they are finished with their training, they need employers to recognise and reward their skills. And finally, they need to be where the ICT jobs are. Including - if it's needed - to move to another EU country. And that should be straightforward to do - after all, that's what the EU is all about. That's quite a shopping list. And I think it's clear why we need a coalition to achieve it. We can't do this alone. But, to quote someone else determined to create jobs, together, yes we can."

1 The book Hacking the Academy is available at http://www.digitalculture.org/hacking-the-academy/hacking-teaching (last accessed February 2014).

2 The whole speech is available at http://europa.eu/rapid/press-release_SPEECH-13-598_en.htm (last accessed February 2014).

International Journal of Transmedia Literacy - 1.1 - December 2015

http://www.ledonline.it/transmedialiteracy/ 
Despite the risk to partially depreciate the master degree with a technical approach we followed both the hackers' advice and Kroes' recommendations. A flexible structure of the course in Public and Social Communication Sciences lets the experiment run. The whole research/action project is based on two on-going questions: 1) is the community a medium? 2) Is students' claimed role in the society the message delivered by the medium? From the answers given directly by students during debates and in social media discussions, or given indirectly in products produced during the workshop, we can infer some considerations.

\section{Placevent and CommUni.Action}

Since February 2013 group of 30 students attending a workshop once a week for 3 months have learnt how to use 2.0 tools, how to create an online community engaging partners and stakeholders as well as how to curate digital content. They became also information seekers and information gatekeepers; they used open-data to create multimedia content, to write news, to edit videos and to elaborate innovative solutions for data visualization. Moreover they became a group and after a year working together a proper team, able to develop independent projects.

In 2008 Jenkins has written: "participatory culture shifts the focus of literacy from one of individual expression to community involvement. The new literacy almost all involve social skills developed through collaboration and networking. These skills build on the foundation of traditional literacy, research skills, technical skills, and critical analysis skills taught in the classroom." (2008: 4) The workshop simulated a work frame with clients asking to solve actual problems. Public bodies and local companies brought their communication problems or projects to develop both in the virtual arena, i.e. posting in Placevent's blog or on the LinkedIn page, and in the offline traditional seminars in class. In these two years the syllabus prepared for \#Placevent's activities was following the steps and the keywords suggested, again, by Jenkins:

- Affiliations: memberships, formal and informal, in online communities centered on various forms of media;

- Expressions: producing new creative forms of content;

- Collaborative Problem-solving: working together in teams, formal and informal, to complete tasks and develop and share new knowledge;

- Circulations: shaping the flow of media. (Jenkins 2008)

The unattainable model that inspired the project was the MIT center for civic media; however \#placevent activities were focused on digital content production and people's empowerment rather than tools and frameworks' design. 
In April 2013 the group of 30 students, who become a community and a proper team in the meanwhile, invited a group of stakeholders to play, i.e. asking questions and challenging them during an open conference. Students decided to organize and to produce in three months a new career-fair format mixing key speakers, professional experiences and a final brainstorming to collect ideas required to draw up guidelines. The conference called CommUni.Action (to assemble all the words describing vision and mission, I.e. communication, community, university and action) was staged at the end of April 2013 and played in 3 parts. The first session, centred on the main speaker, was titled "Guru in Action". Aron Pilhofer, leader of the interactive media team of the New York Times and founder of Hacks and Hackers, had been invited as opening keyspeaker. He charmed the audience with the creations of a team that joins journalists and developers. The second part was the "relay-race" and 10 professionals in 7 minutes talked about a single aspect of their work. Each speech had a hashtag and the community had been invited to ask questions and to comment using the proper \#keyword. The final session was a typical brainstorming "Community in Action" and involved some academics to draw the guidelines of the future of education in Social and Political Communication Studies.

Students posted articles and comments using the blog platform to share information about speakers and topics.

In summer 2013 half of the students attending the Placevent workshop founded a civil society organization, called Placevent [Hub] to continue the activity as well as to pass the baton to the younger students who are attending the new edition of the laboratory. Members of Placevent community (composed by students, professors, researchers or professionals) are not cheerleading digital literacy or fostering a technocratic approach despite a creative and critical one, but transmediality in storytelling seems to emerge naturally and innovation in content production lies in the collaborative approach they use and in digital opportunities able to trigger their ideas.

\section{TEAM WORK AND DIGITAL TOOLKIT}

University students use internet mainly for amusement and not as a learning tool. During the first lesson I asked to the 30 students why and how they access the internet in general and social media in particular. Most of them have a personal computer or a laptop at home, however they use an internet key and they have not a flat internet connection. When they need to do long researches, to watch videos or to talk with someone using VOIP services they use the university wifi connection or the city hall public one. They all have a 
mobile phone, but 15 up to 30 have a smart phone and only 5 have an internet connection. Just 2 students have a flat internet connection on their phones. They explained that both the home internet and the mobile connections are too expensive and they are not able to face a monthly cost for something that is not so relevant. About social networks, only one of them has not a Facebook profile, but on the other side only few of them had a Twitter account. The first assignment during the course were to clean their Facebook personal profile (or to create lists to filter the visibility of their personal data), to create a personal account on Twitter and one on LinkedIn.

Some of the information I collected with this informal interview with students are confirmed by general surveys and other studies. According to Mazzoleni, Vigevani and Splendore (2011): "The question of internet penetration in Italy, with its implications for digital divides, is linked to the diffusion of broadband. Although the growth of broadband still lags behind much of the European Union (EU), it is certainly increasing. There are 11.7 million households with broadband technology (Asymmetric Digital Subscriber Line [ADSL] is most widespread and represents 97 percent of all broadband connections), all with various subscriptions (flat-rate subscriptions for 24-hours internet connections are increasingly common even if the cost remains high despite the market competition among providers). In this field, however, national policies do not seem to be moving in the direction of greater broadband diffusion (investment has been frozen until 2014)."

AGCOM (Italian Agency for Communication) report 2013 about Italy accounts the Internet socio-demographic profile: regardless of location and of device examined, most of the Italian users are young people (over 93\% of individuals aged between 11 and 34 years) and live in densely populated areas, i.e. with more than 100,000 inhabitants. Moreover, high concentration ratios are relevant between the most qualified profiles both in terms of education and employment status, but the Internet access is growing even among other socio-demographic profiles: the AGCOM survey detected a penetration rate of over $90 \%$ for graduates $(97.9 \%)$, high school diploma $(93.2 \%)$, employed in general $(91.1 \%)$ and particularly managers, executives and academics ( $100 \%$ of respondents who hold one of these positions), entrepreneurs and professionals $(97.8 \%)$ and employees and teachers $(97.7 \%)$. College and University students have a very high penetration rate $(99.7 \%$ of college students interviewed say they have internet access), while students in middle and high schools have a penetration rate of $96.6 \%$. More than $40 \%$ of users are on the net to find information $(42.1 \%)$, but there are other relevant goals like the opportunity to find goods or digital content only available on the Web $(26.1 \%)$, a quick access to on-line public and private services $(25.1 \%)$, to be informed in real time about news $(23.5 \%)$. 
These data show that students are a digital equipped target, however does not say anything about their skills and above all how we can translate the Internet access in an employment opportunity. This is one of the main topics we discussed during workshop activities.

\subsection{Bologna as a smart city fostering prosperous communities}

As mentioned above most of the students used the free Wi-Fi connection offered by the University of Bologna or the City Hall. The City of Bologna has a long time and peculiar history of citizens' engagement using civic networks and digital media. This story started in 1996 with a civic network based on the internet and the newborn WWW to last until today. In 1999, 14 years ago, Tambini described the first issues promoted by groups of digital citizens, empowered by the Internet:

[...] initiatives range from using city hall web pages as a more efficient means to make political information available to those who use the Internet, to experiments in electronic voting, to encouraging all citizens to use interactive media to organize interest groups and neighborhood alliances. Although national states have experimented with new media (for example the White House, which offers direct email to the President's office and extensive information on the government program), it is the local experiments - the so-called 'civic networks' - that are most advanced, and offer the clearest insights into emerging patterns of political communication.

Collaboration, digitalization and citizens' involvement are flagged as the main part of Bologna's brand. Putnam (1993) in the Prosperous communities said: "Some regions of Italy, such as Emilia-Romagna and Tuscany, have many active community organizations. Citizens in these regions are engaged by public issues, not by patronage. They trust one another to act fairly and obey the law. Leaders in these communities are relatively honest and committed to equality. Social and political networks are organized horizontally, not hierarchically. These 'civic communities' value solidarity, civic participation, and integrity. And here democracy works."

The general aims of the laboratorial activities of the University of Bologna for Public and Social Communication are planned to give students an opportunity as future professionals or entrepreneurs. The goal is to create a community able to use the web 2.0 as a debate arena exploiting some features of the city and the long tail of the investments the public bodies did in the Nineties, both in terms of infrastructure and in spreading the participative culture, involving students as citizens in the process and continually updating the relationships with public and private players. Moreover the metropolitan city of 
Bologna is just one important node of a wider regional net that connects other interesting experiences like Modena, Reggio Emilia, Ferrara and all the other touristic cities in the East coast (Ravenna, Rimini, Forlì, etc.).

The role of this regional network mirrored partially on the web is everyday growing. A year ago, the Emilia Romagna region faced an earthquake emergency. Citizens had been invited by the authorities to use the Internet to raise actual problems or to ask questions as well as to upload information. Some students attending \#Placevent workshop asked to be actively involved in this process too; they discussed and present an online community engagement, a communication plan and a program of collateral activities in collaboration with a project, called OpenRicostruzione, and promoted by an NGO, ActionAid. In this specific case trasmediality is still used used as a multiplier for the engagement actions not only for content production. Openricostruzione project aims to check the use of funds allocated or collected to rebuild infrastructure destroyed or damaged by the earthquake. University students are helping local communities, groups of journalist and middle school students to create a social, collaborative and multimedia storytelling interviewing the actors, following the traces of the activities, scouting similar experiences as well as collecting data and visualizing them. The quake highlighted also some problems in the communication flow due to bureaucracy and regulation; these difficulties affected mainly the step between the ongoing debate in citizens' arenas and the translation of the public debate in issues to negotiate actual solutions. This interference is visible in the ordinary debate about the digital agenda. Citizens and students are often called to express their opinion, but they are not able to influence the political decisions. Agreements between public bodies, academy and groups of interests present two main features: efforts are aimed to get a digital "smart" cities rather than empowering smart citizens and practical solutions proposed by people are not able to reach the attention of policymakers and administration (Bazzarin and Lalli 2012). \#Placevent hacked this system and the public debate too. One of the secondary question and a goal of this research was to evaluate how much students represent themselves as citizens in Bologna and to promote the use of digital and communitcation skills they have or they are learning to improve city's public communication about grants, conferences, meetings, awards and job opportunities in the social media.

\subsection{Placevent $[H U B]$ as a prosperous community}

The community of Placevent now is composed by two sub-communities: one composed by the students attending the second edition of the workshop and the other one around the civil society organization, Placevent [HUB], created by the 
graduate students who attended the first edition. The new group of 20 students attending the second edition of the workshop, started in October 2013, are not engaged in the vision and in the mission as the students of the first edition were, so we are collecting data to understand why we are not able to intercept their needs or to succeed in creating a new team. Placevent [HUB] aims to continue to catalyze community-based micro innovation practices of a) high impact in a small scale - but with a scalable effect - engaging personal networks and online social media platforms; b) effectively bottom-up, i.e. arising from the idea of a small team able to reach policy makers as well as to improve the degree program with digital skills; c) innovative, using ICT as fuel to empower creativity and innovation in sectors like communication, journalism, education and civic activism. Moreover senior students are witnessing their passion and telling their project to the group of junior ones, but they are not able to bridge the different experiences and the interactions between the two groups results occasional in the online arenas the two communties share too.

According to what we highlighted in a previous paper in which we analyzed a similar workshop experience (Bazzarin and Lalli 2011) students have now the chance to explore "new boundaries or social ties; different opportunities to share, buy or to exchange goods; the option to participate actively in public debate; access to information; the opportunity to produce information. We suppose that ritual practices of the Internet and social media interaction are developing, although these have not been codified. In virtual communities we can observe a process supporting and enhancing shared social meanings and identities." Observing the activity Placevent [HUB] is possible to confirm that individuals identify themselves with more than one community contemporaneously and serially, changing affiliations with great fluidity. For instance two of the members founded a start-up with another graduate student that is not involved in the association activity. However if the community's focus pertains their actual interests (i.e. job search and personal visibility), a core of people remains engaged in the community especially they consider themselves founder of a group that reflects their values and has a positive impact on their personal reputation. The Internet represents a tool to exert personal and social influence, complicating the famous two-step flow of communication by Lazarsfeld. Bazzarin and Lalli (2012) suggest a "scattered-step flow of communication" where opinion leaders are spread in the network and they can quit or be dismissed from this role quickly and not regretfully, "in fact the main consideration we draw from a pilot ethnographic observation of these two case studies is the fluidity of membership. Consequently roles are transient too". This lack of persistence probably explains why the rise and fall of social networks (paraphrasing the title of Hilgartner and Bosk's 1988 paper) "is becoming so quick and weak on the long term period" (Bazzarin and Lalli 2011), even if we can add 
that is possible to extend the life of these networks as long as you accept that roles of members, mission and vision would be updated or negotiated often.

Literature about community and online community counts many authors and definitions. First, there is community in a topographical sense. This refers to settlement based upon close geographical propinquity, but where there is no implication of the quality of the social relationships found in such settlements of intense co-presence. Second, there is the sense of community as the local social system in which there are localised, relatively bounded set of systemic interrelationships of social groups and local institutions. Third, there is communion, a human association that is characterised by close personal ties, belongingness and warmth between its members. According to Putnam (2000) these are what is conventionally meant by the idea of 'community' relationships. Moreover we will discuss if this phenomenon is new or innovative and what implies in terms of self representation. In fact, according to Jenkins: "In such a world, many will only dabble, some will dig deeper, and still others will master the skills that are most valued within the community. The community itself, however, provides strong incentives for creative expression and active participation. Historically, we have valued creative writing or art classes because they help to identify and train future writers and artists, but also because the creative process is valuable on its own; every child deserves the chance to express him - or herself through words, sounds, and images, even if most will never write, perform, or draw professionally. Having these experiences, we believe, changes the way youth think about themselves and alters the way they look at work created by others." (Jenkins 2008, 7)

\subsection{Translating fragmented identities in a collaborative storytelling}

Corinne Weisgerber Assistant Professor of Communication St. Edward's University has written": "Stages merge and audiences become fluid. When I enter the Twittersphere, digital audiences aren't as easy to define any longer. Yes, there's my primary audience composed of the people who chose to follow me on Twitter. But to think that that's my only audience might be a bit naïve. All it takes is one re-tweet for my message to leave the confines of my own Twitter network and to reach new audiences. Of course, my tweets also live on my Twitter profile, which if set to public, means that my potential audience has just grown to pretty much anyone with an Internet connection. And let's not

3 The book is downloadable at: http://academic.stedwards.edu/socialmedia/blog/2011/11/16/ negotiating-multiple-identities-on-the-social-web-goffman-fragmentation-and-the-multiverse/\#sthash. pbGP3iUb.dpuf (last accessed February 2014).

International Journal of Transmedia Literacy - 1.1 - December 2015

http://www.ledonline.it/transmedialiteracy/ 
to forget the Library of Congress, which in 2010 announced plans to acquire every publicly shared tweet since 2006. Let's think about this! One day, years from now, my great-grandkids - an audience that doesn't even exist yet - might be reading my tweets through the Library of Congress archive. With all these potential audiences, how are we supposed to know any longer who we will be performing for? To make matters even more complicated, thanks to cyberspace, I can also be present in multiple places at once. In Goffman's terms, I can now perform different plays to different audiences at the same time. Just think of a tweet: I can send it out via Twitter and simultaneously post it to Facebook and pull it into my blog, all of which have different audiences and serve different self presentational needs. That poses a problem though: Facebook Corinne and Twitter Corinne are not the same persona. And they're also slightly different from Corinne, the blogger. I'm a lot pickier about whom I let join my Facebook network and I rarely let mere acquaintances in. If you want to connect with me on Facebook, I have to know you fairly well. As a result, you'd probably get to see a much more unfiltered version of Corinne than you would on Twitter." Corinne is a professor and researcher and, despite the fact she calls her follower audiences, instead of active public, she tries to present a very professional image and to engage actors on multiple stages with multiple sometimes overlapping audiences using a social media. We used an horizontal approach to empower students' potential instead of replicating in the web based community the typical pyramidal structure of the academy. But we agree when Prof. Weisgerber highlights that our online identities are fragmented. "Partly because the web has become fragmented with walled communities popping up everywhere. As a social media professor, I feel pressured to keep up with these communities, so naturally I set up shop in them as soon as a new one arrives. In fact, I have created identities in so many of these services that I have no idea how many parts of me are floating around the Internet." Students participating in our workshop experienced the same frustration, however we decide to reduce the number of personal accounts they have and to aggregate information around two main channels, the blog placevent.wordpress.com and the class during workshop.

Moreover we assigned roles to account each student on a project, to do not waste the energy, and to give a reference easily accessible to our clients. In this way we hope to moderate both the fragmentation of the roles and the disengagement from the working group after students obtain the formal credits for the workshop.

Results show a good impact of the activity in students' digital skills portfolio (we reviewed participants' LinkedIn resumes before and after the workshop) and networking expertise, however risky assessment about privacy, personal data, cyber-bullism, accountability and copyrights has required a major effort to face a general lack of attention and interest. To face the selfish 
attitude to not share the best opportunities with the group and to focus also on the less glamorous issues we decided to write some post on the blog, rotating the authors or by assigning tasks to those who tended to stay always in the second line.

As moderator of the community interactions (both online and offline) and as mediator with the academy requirements the main challenge was to balance the individual desire to exploit the blog and the network as a diving board into the world of work Vs the team-work implied in building a community starting from the blog. Intentions behind participation were different and 10 students after they accomplished the compulsory part of the program (until the event communi.Action) decided to leave the project during the first edition. Among the remaining 20 there were tensions for personal reasons or due to different opinion. The funders group that decided to carry on the community is composed of 15 people.

\section{NOT A CONCLUSION BUT A STEP FORWARD}

Jenkins highlighted that: "Rather than dealing with each technology in isolation, we would do better to take an ecological approach, thinking about the interrelationship among all of these different communication technologies, the cultural communities that grow up around them and the activities they support. Media systems consist of communication technologies and the social, cultural, legal, political, and economic institutions, practices, and protocols that shape and surround them. (Gitelman 1999) The same task can be performed with a range of different technologies, and the same technology can be deployed toward a variety of different ends. Some tasks may be easier with some technologies than with others, and thus the introduction of a new technology may inspire certain uses. Yet, these activities become widespread only if the culture also supports them, if they fill recurring needs at a particular historical juncture. It matters what tools are available to a culture, but it matters more what that culture chooses to do with those tools." $(2008,8)$

Despite the general problem to find a decent employment for people with a humanistic background showed by data provided, students participating in \#placevent project felt empowered by witnessing their presence in the city of Bologna and in its public sphere, by belonging to a group promoting innovation through practices of communication, as well as by overlapping and matching networks of relationships and widening the community or engaging new shareholders. Social media spaces are open, organizable and organized as actual traditional arenas are. This fluidity of boundaries, rules and roles needs 
to be described both maintaining the heritage of previous descriptions (McLuhan's 1962 or Castell's 1996) and by understanding the characteristics of interactive digital media, such as the rise of ritual fluid identities, the opportunity to create the content as well as to learn sharing knowledge with peers and the trend to translate the fluid membership or the fragmentation of identities in the web in an effective portfolio of skills and experiences.

As Aron Pilhofer said during Communi.Action: "Part of the goal, of the use of social media is that they're inherently interactive, it is a two-way conversation, a technology that allows you to truly interact with readers [...] believe it or not, anyone who uses social would say "of course it does, that's silly!", but there are a lot of editors that don't think that social has that. If they think about the social at all, they think as a way to deliver content, as a way to send links [...] but there's much much more than that". We witness this selective blindness in the Italian academy as well as in local policies daily and students decided to implement a micro-hacking civic activity from the place in which they felt more comfortable: a specific project aimed to help them to find a position in the society and to access the public sphere producing social and public communication. The answer is a blog, their blog, to use social network's wires and links to make the process visible and effective thought capillarity (and to get a job, we hope!).

\section{REFERENCES}

AGCOM. 2013. Relazione annuale 2013 sull'attività svolta e sui programmi di lavoro. Napoli: Autorità Garante per le Comunicazioni.

AGCOM. 2012. Annual report 2012. Lines of intervention and prospects for developments. 2011 activities and results summing-up the 3-year mandate. Roma. Telecom.

Altman, Irwin. 1975. The environment and social behaviour: Privacy, personal space, territory, and crowing. Monterey, CA: Brooks/Cole.

Bandura, Albert. 2001. "Social cognitive theory of mass communication", in Media Psychology 3: 265-299. doi: 10.1207/S1532785XMEP0303_03.

Bazzarin, Valentina, and Pina Lalli. 2012. "Collective tellers. Web collaboration: two examples", in Multi-faceted nature of collaboration in contemporary world, edited by T.B. Valic, D. Modic, U. Lamut, 116-129. London: Vega Press Ltd.

Bazzarin, Valentina, and Pina Lalli. 2011. "The Medium is the Community: A pilot laboratorial activity at University of Bologna to tell and promote the city", in McLuban Galaxy Conference. Understanding Media, Today, edited by Ciastellardi, Matteo, Cristina Miranda de Almeida, and Carlos Scolari, 323-330. Barcelona: Editorial Universitat Oberta de Catalunya. 
Bazzarin, Valentina, Marco Scarcelli, and Stefano Ghirlanda. 2011. "Caribbean Pirates or Robin Hood's crowd? Perceptions of Illegal Behaviors and warning signals in Internet seas and forests comparing American and Italian adolescents' perspective”, in McLuban Galaxy Conference. Understanding Media, Today, edited by Ciastellardi, Matteo, Cristina Miranda de Almeida, and Carlos Scolari, 56 59. Barcelona: Editorial Universitat Oberta de Catalunya.

Boyd, Danah, and Nicole Ellison. 2008. "Social network sites: Definition, history, and scholarship", in Journal of Computer-Mediated Communication, 13 (1): 210-230.

Castells, Manuel. 1996. The rise of the network society, Cambridge, MA; Oxford: Blackwell.

Castells, Manuel, and Gustavo Cardoso. 2006. The Network society: from knowledge to policy. Washington: Center for Transatlantic relations.

Child, Jeffrey T., and Esther A. Agyeman-Budu. 2010. "Blogging privacy management rule development: The impact of self-monitoring skills, concern for appropriateness, and blogging frequency", in Computers in Human Behavior 26: 957 963. doi: 10.1016/j.chb.2010.02.009.

Child, Jeffrey T., Paul. M. Haridakis, and Sandra Petronio. 2012. "Blogging privacy rule orientations, privacy management, and content deletion practices: The variability of online privacy management activity at different stages of social media use", in Computers in Human Behavior 28: 1859-1872. doi: 10.1016/j. chb.2012.05.004.

Child, Jeffrey T., Judy C. Pearson, and Sandra Petronio. 2009. "Blogging, communication, and privacy management: Development of the blogging privacy management measure", in Journal of the American Society for Information Science and Technology 60: 2079-2094. doi: 10.1002/asi.21122.

Evans, Elizabeth. 2011. Transmedia television: audiences, new media and daily life. New York: Routledge.

Florida, Richard. 2011. The Rise of the Creative Class. Rivisited. New York: Basic Books.

Gitelman, Lisa. 1999. Scripts, Grooves, and Writing Machines: Representing Technology in the Edison Era, Stanford, CA: Stanford University Press.

Jenkins, Henry, 2008. Confronting the Challenges of Participatory Culture: Media Education for the 21St Century available online. Last access January 1, 2014. URL: http://digitallearning.macfound.org/atf/cf/\%7B7E45C7E0A3E04B89AC9CE 807E1B0AE4E\%7D/JENKINS_WHITE_PAPER.PDF.

Johnson, Norman A. 2009. "Anger and flaming in computer-mediated negotiations among strangers”, in Decision Support Systems 46 (3): 660-672. doi: 10.1016/j. dss.2008.10.008.

Kaplan, Andreas. M., and Michael Haenlein. 2010. "Users of the world, unite! The challenges and opportunities of Social Media." Business Horizon 53: 59-68. 
Katz, Elihu, Jay G. Blumler, and Michael Gurevitch. 1973. "Uses and gratifications research.” The Public Opinion Quarterly 37: 509-523. doi: 10.1086/268109.

Kietzmann, Jan H., Kristopher Hermkens, Ian P. McCarthy, and Bruno S. Silvestre, 2011. "Social media? Get serious! Understanding the functional building blocks of social media." Business Horizons, 54(3): 241-251.

Levy, Pierre. 2000. Collective Intelligence: Man's Emerging World in Cyberspace. New York: Perseus.

Livingstone, Sonia. 2003. The Changing Nature and Uses of Media Literacy. Working paper. London: London School of Economics.

McLuhan, Marshall. 1964. Understanding media; the extensions of man, New York: McGraw-Hill.

Lampe, Cliff, Nicole Ellison, and Charles Steinfield. 2006. "A Face(book) in the crowd: Social searching vs. social browsing”, in Proceedings of the 2006 20th anniversary conference on computer supported cooperative work, 167-170. New York: ACM Press. doi: 10.1145/1180875.1180901.

Lampe, Cliff, Nicole Ellison, and Charles Steinfield. 2007. "A familiar Face(book): Profile elements as signals in an online social network", in Proceedings of the SIGCHI conference on buman factors in computing systems, 435-444. New York: ACM Press. doi: 10.1145/1240624.1240695.

Lampe, Cliff, Nicole Ellison, and Charles Steinfield. 2008. "Changes in use and perception of Facebook." in Proceedings of the 2008 conference on computersupported cooperative work, 721-730. New York: ACM Press, doi: 10.1145/ 1460563.1460675 .

Lampe, Cliff, Rick Wash, Alcides Velasquez, and Elif Ozkaya. 2010. "Motivations to participate in online communities." In Proceedings of the 28th international conference on buman factors in computing systems, 1927-1936. New York: ACM, doi: 10.1145/ 1753326.1753616.

Papacharissi, Zizi, and Alan M. Rubin. 2000. "Predictors of Internet use.” Journal of Broadcasting E Electronic Media 44: 175-196. doi: 10.1207/s15506878jobem4402_2.

Papacharissi, Zizi, and Andrew Mendelson. 2007. "An exploratory study of reality appeal: Uses and gratifications of reality TV shows." Journal of Broadcasting and Electronic Media 51: 355-370. doi: 10.1080/08838150701307152.

Papacharissi, Zizi, and Andrew Mendelson. 2011. "Toward a new(er) sociability: Uses, gratifications and social capital on Facebook", in Media perspectives for the 21st century, edited by Papathanassopoulos S., 212-230. New York: Routledge.

Park, Namsu, Kerk F. Kee, and Sebastián Valenzuela. 2009. "Being immersed in social networking environment: Facebook groups, uses and gratifications, and social outcomes" in CyberPsychology \& Behavior 12: 729-735. doi: 10.1089/ cpb.2009.0003.

Putnam, Robert. D. 1993. "The Prosperous Community: Social Capital and Public Life." The American Prospect 13: 35-42. 
Putnam, Robert. D. 2000. Bowling Alone: The Collapse and Revival of American Community. New York: Simon and Schuster.

Tambini, Damian. 1999. "New Media and Democracy: The Civic Networking Movement." New Media E Society 1: 305-329. doi:10.1177/14614449922225609

Treré, Emiliano, and Valentina Bazzarin. 2012. "Anatomy of the Italian Web TV ecosystem. Current issues and future challenges", in Digital Communication Polices in the Information Society Promotion Stage, edited by De Nicoli and Sousa, 87-110. Minho: Communication and Society Research Centre (CECS), University of Minho.

Treré, Emiliano, and Valentina Bazzarin. 2011. "Exploring Italian Micro Web TVs: how high-Tech bricoleurs redefine audiences?" ESSACHESS - Journal for Communication Studies 4: 35-37. 